\title{
EVALUATION OF THE AIR POLLUTION IMPACT OF HEAVY GOODS, DIESEL DRIVEN VEHICLES, ALONG THE A1 HIGHWAY IN NORTH MACEDONIA
}

\author{
Nikola Manev $^{1 *}$, Dame Dimitrovski ${ }^{2}$, Elenior Nikolov ${ }^{1}$, Drage Petreski $^{1}$, \\ Zoran Markov², Viktor Iliev ${ }^{2}$ \\ I"Military academy "General Mihailo Apostolski”, Skopje, Vasko Karangeleski, bb, North Macedonia; \\ ${ }^{2}$ Faculty of Mechanical Engineering, Skopje, Karposh II, bb, North Macedonia; \\ *Corresponding Author Nikola Manev, e-mail: manev.nikola@yahoo.com;
}

Received July 2021; Accepted August 2021; Published September 2021;

DOI: https://doi.org/10.31407/ijees11.426

\begin{abstract}
Road traffic is a major source of air pollution due to emissions of a range of pollutants but most notably CO, NOx, NMVOC and particulate matter (PM) emissions, which have a strong association between their concentration and respiratory system diseases. Diesel engines have the highest emission rates of these pollutants as they dominate heavy-duty applications due to their greater fuel efficiency, power output and ability to haul bigger loads. This also means higher quantities of non-exhaust emissions per vehicle, as the load distribution, and the size of the vehicle, factor in the quantity of brake and tire wear emissions. This implies that the presence of exhaust pollutants and nonexhaust PM and their impact to the environment has been exacerbated by the presence of heavy goods vehicles (HGVs). Multiple reports on North Macedonia's air pollution management claim that national emissions inventories report all key sources of pollution but need to strengthen inputs for the transport sector as there is a need to validate the consistency of transport data used in the inventory and further capture context-specific features of important local emission sources. In this context, since the average emissions of HGVs vary significantly as a result of the different mission profiles, payloads, mileage and vehicle age of an HGV, this paper defines a typical HGV model for North Macedonia and then provides an analysis and an estimate on the emissions footprint of the HGVs transiting the Macedonian A1 highway, thereby gathering a significant part of the aforementioned specific data on transport in the country.
\end{abstract}

Key words: HGVs, diesel, air pollution, impact, emissions, evaluation 